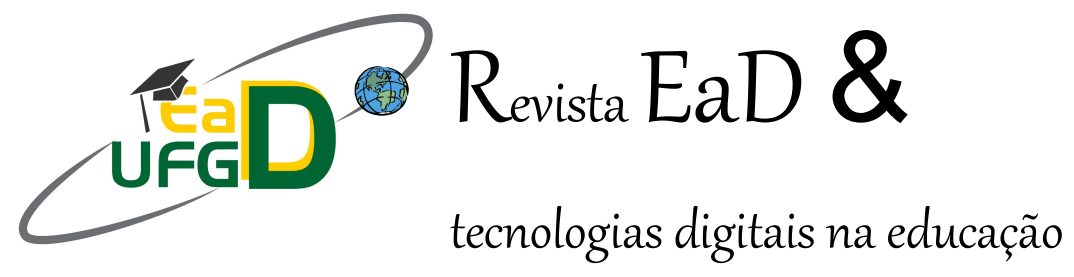

\title{
O Uso das TIC's por Surdos: relato de experiências
}

\begin{abstract}
Eliane Francisca Alves da Silva Ochiuto ${ }^{16}$, UFGD
Resumo: O termo "inclusão" expressa uma necessidade inadiável nesta sociedade do conhecimento, interligada pelas redes digitais: inclusão social, inclusão digital, inclusão escolar. O relato de experiência, é fruto da realização do Subprojeto "O uso das Webtecnologias por portadores de deficiência auditiva", que fez parte do Projeto de Extensão O uso das Webtecnologias na Educação Básica de Nova Andradina e Região, em uma "escola inclusiva" da Educação Básica de Nova Andradina, no ano de 2009-2010 visando a sua inclusão digital e, consequentemente, contribuindo para a sua inclusão social. As ações foram estruturadas em torno do ensino-aprendizagem da leitura e da escrita no meio digital (os hipertextos), em horário extraclasse, através dos recursos da Web interati$v a$, tais como e-mails, chats, fóruns de discussão, blogs e wikis. Mediante as ações realizadas pelo subprojeto, tivemos como expectativas que os envolvidos no projeto se apropriassem de novas ferramentas tecnológicas, culturais e intelectuais, que Ihes permitissem uma integração mais ampla no contexto escolar e social onde viviam, mas também que a sociedade se sensibilize para o fato de que os mesmos podem desenvolver o seu potencial como qualquer outro aluno normal, desde que devidamente assistidos em seu contexto familiar e/ou escolar.
\end{abstract}

Palavras-chave: Surdos, TIC's, Aprendizagem de Língua.

\section{Introdução}

Ao decidir tornar-se uma sociedade inclusiva, subscrevendo uma série de acordos internacionais e produzindo uma legislação que contempla esse modelo inclusivo, o Brasil se comprometeu a construir um sistema de educação inclusiva para pessoas com deficiência, que consiste no "reconhecimento da necessidade de se caminhar rumo à escola para todos; um lugar que inclua todos os alunos, que celebre a diferença, apoie a aprendizagem e responda às necessidades individuais". Também, conforme se verifica

\footnotetext{
${ }^{16}$ Mestre em Letras. Professora do Curso de Letras Libras da UFGD. Coordenadora UAB/UFGD.
} 
na Lei de Diretrizes e Bases da Educação Nacional, de dezembro de 1996, a intenção é de que a educação das pessoas com deficiência, ocorresse, preferencialmente, na rede regular de ensino. Por isso, há que se pensar, com urgência, na efetivação do direito dessas pessoas.

Paralelamente a esse processo, vê-se também o crescente processo de informatização da sociedade, que "exige" que todas as pessoas tornem-se participantes ativos do mundo digitalizado. No que se refere as pessoas com deficiência, o advento da era digital trouxe um novo desafio para a sua efetiva inclusão social: promovendo o letramento digital das pessoas com deficiência, da mesma forma que vem sendo feito com os alunos ditos "normais". Dada a minha condição de estar incluída na classe de pessoas com deficiência, sendo Surda, acredito ser possível promover a inclusão digital, embora o caminho não seja fácil porque ainda é pouco conhecido. Mas, não custa tentar. Este foi o desafio enfrentado com a proposta de trabalho de extensão desenvolvido ainda na época da graduação com pessoas surdas. Na qual, esses foram os primeiros passos na luta contra o preconceito e a aceitação da diversidade como ponto de partida para a efetivação do novo paradigma social.

O projeto de extensão intitulado "O uso das Webtecnologias por portadores de deficiência auditiva", teve como objetivo: a) Conscientizar o participante da necessidade da inclusão digital na Sociedade do Conhecimento deste terceiro milênio; b) dar base aos participantes de ações necessárias para o domínio das Webtecnologias; c) Abordar as técnicas de busca de informações e referências na Web, utilizando mecanismos de busca na Web de forma mais eficaz; d) Iniciar e /ou aperfeiçoar o uso das Webtecnologias, através não somente do trabalho com hipertextos, inclusive colaborativos, como também com os ambientes virtuais de aprendizagem colaborativa e os canais interativos informais da Net, tais como os blogs, e-mails, chats, fóruns de discussão e Wikis; e) Propiciar noções fundamentais de ética no uso da rede ("netiqueta"), conscientizando o participante da importância dessa ética para o bem-estar social.

Diante dos objetivos elencados como parte do projeto, o presente relato de experiência sobre o mesmo se divide nos seguintes subtemas: das visadas teóricas, metodologia, considerações finais.

\section{Das visadas teóricas}

A exclusão e marginalização reduzem as oportunidades das pessoas com deficiência, não somente no que diz respeito as suas condições de vida, mas principalmente à possibilidade de contribuir de forma produtiva na sua família, na sua comunidade e no país. Desde 1988, com a promulgação da atual Constituição, que o Brasil vem encarando a enorme e difícil tarefa de ressarcir a enorme dívida social acumulada ao longo de sua história, produto de vários fatores sociais, políticos e econômicos. Uma dessas desigualdades diz respeito a essas pessoas, cuja inclusão escolar e social somente há alguns anos vem sendo contemplada, embora de forma ainda bem precária.

Segundo o Grupo Takano (s.d.), o debate sobre a necessidade de um conjunto específico de leis para este segmento da população adquire um espaço fundamental no âmbito internacional - principalmente na Organização das Nações Unidas (ONU) - em 1987. Naquele ano, a ONU realizou o Encontro Global de Especialistas para a Implementação de um Programa de Ação Mundial, cujo ponto central de discussão e debate foi o de garantir os direitos das pessoas com deficiência. Em 1990, três anos após o primeiro 
encontro, a ONU tentou, mais uma vez, elaborar uma agenda de discussão que permitisse estabelecer um conjunto de princípios de caráter obrigatório para a promoção dos direitos e garantias dessas pessoas.

Apoiada por grande número de organizações não governamentais (ONGs), finalmente a pressão política pela realização de uma convenção internacional patrocinada pela ONU surtiu efeito em março de 2000, através de um novo encontro realizado em Pequim (Beijing), onde foi aprovada uma declaração de direitos denominada de Declaração de Beijing sobre os Direitos das Pessoas com Incapacidades no Novo Século.

O Brasil adotou o novo paradigma de tornar-se uma sociedade inclusiva, produzindo uma legislação que se compromete com este modelo inclusivo, buscando não somente conscientizar a sociedade brasileira sobre a necessidade da inclusão dessas pessoas, mas também mobilizar a área educacional para que se adaptasse e se preparasse para atender as necessidades das mesmas. Ao aceitar a Declaração Mundial de Educação para Todos, firmada na Tailândia em 1999 e ao concordar com os postulados da Conferência Mundial sobre Necessidades Educacionais Especiais, produzidos em Salamanca, (Espanha, 1994), o Brasil oficializou o "reconhecimento da necessidade de se caminhar rumo à escola para todos, um lugar que inclua todos os alunos, celebre a diferença, apoie a aprendizagem e responda às necessidades individuais".

No final do século $X X$, no limiar do terceiro milênio, com o surgimento da rede mundial de computadores, a Web, acessada pela Internet, iniciou-se a "revolução digital, sendo que, a cada minuto, novos computadores se interconectam na Internet, novas informações são injetadas na rede. Houve um aumento inacreditável de conhecimentos, os quais agora estão ao alcance de todos os que têm acesso à Internet. É a interatividade total, a inteligência coletiva da humanidade em ação, a sociedade em rede. Pela primeira vez na história, temos a possibilidade de integrar, com facilidade, rapidez e criatividade, todos os tipos de mídia: a palavra, a imagem, o som, a animação etc.

Dessa forma, estamos diante do surgimento de um novo texto, muito diferente dos tradicionais textos impressos, um texto todo "cortado", fragmentado por links, além de "mesclado" com todos os tipos de signos, o chamado hipertexto digital. Segundo Pierre Lévy (2003, p. 92), esse novo ambiente cultural constitui o ciberespaço, ou seja, "o espaço de comunicação aberto pela interconexão mundial dos computadores e das memórias dos computadores (...)" . Com o ciberespaço, desenvolveu-se um novo ambiente cultural, a cibercultura, termo criado também por Lévy, em que o saber da humanidade não se acha mais centralizado em qualquer espaço físico, nos livros, nas instituições: “(...) a informação [...] está virtualmente presente em cada ponto da rede onde seja pedida" (p. 48). É aí que Lévy situa a nova "inteligência coletiva da humanidade", movida pela autonomia e pela abertura para a alteridade: o papel da informática e das técnicas de comunicação com base digital não seria "substituir o homem", nem aproximar-se de uma hipotética "inteligência artificial", mas promover a construção do saber coletivo da humanidade. Lévy acrescenta ainda que a participação nesse saber coletivo tornou-se um direito de todos os cidadãos da nova era do conhecimento. Nesse sentido, as tecnologias digitais acabaram por desenvolver formas inéditas de comunicação, em constante e rápida evolução, exigindo um novo tipo de letramento digital.

Atualmente, já se fala na segunda geração da Web. Assim, a expressão "Web 2.0" está por todo lado, em notícias de jornais e revistas, programas de rádio e televisão, sites informativos e de entretenimento. No entanto, segundo Bertocchi (2007, não paginado), "não há consenso sobre o que seja a Web 2.0". Alguns julgam que se trata da 
"idade de ouro da Internet"; outros, mais críticos, consideram o conceito "pura estratégia de marketing empresarial". Segundo Tim O’Reilly, o criador do termo Web 2.0, tratase da "emergência de uma nova geração de tecnologias [...]no qual exista alguma forma de interação coletiva" (apud BERTOCCHI, 2007, não paginado). Dessa foram, o termo Web 2.0 está, portanto, ligado à ideia de "inteligência coletiva da humanidade", proposto por Pirre Lévy (1999), segundo o qual várias cabeças pensam melhor. Conferindo à web 2.0 é considerada por Bertocchi como a "arquitetura da participação". Essa participação é operacionalizada, na Web, pelos chats, blogs, fóruns de discussão, comunidades de aprendizagem interativa, wikis etc.

Alguns pesquisadores, dentre os quais Santa Rosa (2002), têm focalizado as possibilidades de criar novas alternativas para a Educação Especial, com o apoio das tecnologias digitais da informação e comunicação (TIC), presentes no mundo atual, trazendo, inclusive, experiências que destacam a exploração de ambientes virtuais com o objetivo de promover a inclusão digital/social das pessoas com deficiência.

Segundo a autora, "as ferramentas de comunicação e interconexão abrem um leque de oportunidades, principalmente para os sujeitos cujos padrões de aprendizagem não seguem os quadros típicos de desenvolvimento (não paginado) " Para Santa Rosa, "pessoas limitadas por deficiências não são menos desenvolvidas, mas sim desenvolvem-se de forma diferenciada". Por essa razão, a autora vê inúmeras "possibilidades dos ambientes virtuais poderem ser assumidos como recursos para o desenvolvimento, a interação e a inclusão digital/social de pessoas com necessidades educativas especiais" (id).

\section{Metodologia}

O desenvolvimento do projeto contou com a participação de vinte surdos, que eram atendidos pelo Núcleo Municipal de Educação Especial de Nova Andradina/ MS NUMESP/NA, divididos em três turmas, com cerca de duas horas semanais presenciais (bled learning) e duas horas, em média, não presenciais (e-learning), perfazendo um total de 12 horas. As oito horas restantes foram dedicadas ao preparo das atividades.

O ambiente virtual escolhido para o trabalho foi o MOODLE/UEMS, que apresentava todas as ferramentas necessárias para serem utilizadas neste Subprojeto (correio eletrônico, chat, blog, fórum de discussões e Wiki), além de permitir a disponibilização de textos, páginas da Web, imagens e vídeos. Entretanto, esse ambiente pode ser complementado por outros softwares gratuitos disponíveis, tais como o LINUX EDUCACIONAL, os diversos serviços de correio eletrônico (YAHOO e HOTMAIL), o GOOGLE (site de busca) e os hipertextos disponíveis na Web.

O conteúdo tratado foi multidisciplinar, envolvendo temas de escolha dos alunos, bem como conteúdo das disciplinas curriculares, especialmente os temas transversais de saúde, trabalho, segurança e meio ambiente. As atividades envolvendo leitura e produção hipertextual de ficção e lazer também foram contempladas.

Para a realização das atividades, foi necessária uma análise do nível de conhecimento do grupo quanto ao uso de computadores, para que fosse realizado um treinamento preliminar para o uso das operações básicas de acessar, teclar, configurar, salvar e imprimir arquivos etc., bem como do uso de mecanismos de busca na Internet. As ações principais dizem respeito ao aprendizado do uso de e-mails, chats, blogs, fóruns de discussão e wikis, através do ambiente educacional-virtual MOODLE/UEMS. O enfo- 
que foi o uso hipertextual desses recursos, através da habilidade de leitura e compreensão dos hipertextos da Web, do manuseio de links e da inserção de recursos multimídia (imagens, animação e vídeos).

O desempenho dos alunos foi avaliado através do acompanhamento das atividades realizadas durante a realização das mesmas considerando-se, principalmente, o domínio adquirido da tecnologia e a qualidade das tarefas executadas.

\section{Considerações Finais}

Durante a realização do projeto, os participantes tiveram uma boa participação; no decorrer do desenvolvimento das atividades demonstraram interesse em aprender e vencer seus próprios limites frente ao desconhecido.

Os sujeitos do projeto conseguirem entender e compreender a importância de estar inserido no "mundo" da web, e o quanto o acesso as TIC's e o bom uso dessas ferramentas podiam ser fortes aliada para que conseguissem estar inseridos de uma forma mais precisa na sociedade digital, como também para o aprendizado das línguas que são seu meio de comunicação com o mundo, a Língua de Sinais e a Língua Portuguesa.

Com o aprendizado de como fazer uso das ferramentas tecnológicas, os participantes conseguiram estabelecer uma comunicação por meio da escrita, via chats, emails, com seus pares residentes fora de do munícipio em que residiam, como também conhecer outros lugares por meio da internet. Enfim, o subprojeto de extensão ao término de suas atividades conseguiu alcançar os objetivos propostos.

\section{Referências}

BERTOCCHI, Daniela. O que é (afinal) a Web 2.0? Disponível em http://www.educarede.org.br/educa/index.cfm?pg=internet_e_cia.informatica_principa I\&inf_escola=653. Acesso em: 27 jul/2008.

BRASIL/SENADO NACIONAL. Estatuto da pessoa com deficiência. Brasília: Senado Nacional, 2003.

DECLARAÇÃO DE SALAMANCA E LINHA DE AÇÃO SOBRE NECESSIDADES EDUCATIVAS ESPECIAIS. Brasília: Corde, 1997.

DECLARAÇÃO DOS DIREITOS DAS PESSOAS PORTADORAS DE DEFICIÊNCIA. Disponível em: www.saci.org.br. Acesso em: 07 out./2008.

DECLARAÇÃO MUNDIAL SOBRE EDUCAÇÃO PARA TODOS. In: Conferência Mundial sobre Educação para Todos: satisfação das necessidades básicas de aprendizagem. Jomtien/Tailândia, 1990. Disponível em: http://www.direitoshumanos.usp.br/ documentos/tratados/educacao1/declmundeductodos.htm. Acesso em: 07 out/2008.

GRUPO TAKANO. Programa inclusivo para portadores de necessidades especiais. [pp_portadores.pdf].

LÉVY, Pierre. As tecnologias da inteligência. Rio de Janeiro: Editora 34, 1993.

. Cibercultura. 2. ed., São Paulo: Editora 34. 2003. 
SANTAROSA, Lucila Maria Costi. Inclusão digital: espaço possível para pessoas com necessidades educativas especiais. Revista do Centro de Educação, nำ 20, 2002.

TAVARES, Neide Rodrigues Barea. In: I Seminário ATIID - Acessibilidade, Tecnologia da Informação e Inclusão Digital. São Paulo, 28-29/08/2001. Disponível em: www.fsp.usp.br/acessibilidade. Acesso em 07 out/2008.

VALENTE, José Armando. Análise dos diferentes tipos de software usados na educação. In: J.A. Valente (org), O computador na sociedade do conhecimento. Campinas: Unicamp/Nied, 1999. 